\title{
Heat demand mapping and district heating grid expansion analysis: Case study of Velika Gorica
}

\author{
Hrvoje Dorotić ${ }^{1, *}$, Tomislav Novosel ${ }^{1}$, Neven Duić ${ }^{1}$, and Tomislav Pukšec ${ }^{1}$ \\ ${ }^{1}$ Faculty of Mechanical Engineering and Naval Architecture, Department of Energy, Power Engineering and Environment, \\ University of Zagreb, Zagreb, Croatia
}

\begin{abstract}
Highly efficient cogeneration and district heating systems have a significant potential for primary energy savings and the reduction of greenhouse gas emissions through the utilization of a waste heat and renewable energy sources. These potentials are still highly underutilized in most European countries. They also play a key role in the planning of future energy systems due to their positive impact on the increase of integration of intermittent renewable energy sources, for example wind and solar in a combination with power to heat technologies. In order to ensure optimal levels of district heating penetration into an energy system, a comprehensive analysis is necessary to determine the actual demands and the potential energy supply. Economical analysis of the grid expansion by using the GIS based mapping methods hasn't been demonstrated so far. This paper presents a heat demand mapping methodology and the use of its output for the district heating network expansion analysis. The result are showing that more than $59 \%$ of the heat demand could be covered by the district heating in the city of Velika Gorica, which is two times more than the present share. The most important reason of the district heating's unfulfilled potential is already existing natural gas infrastructure.
\end{abstract}

\section{Introduction}

European Union (EU) has recognized energy efficiency, renewable energy sources and carbon dioxide $\left(\mathrm{CO}_{2}\right)$ reduction as the 3 main pillars of its energy and climate strategy. Specific targets have been appointed for the period until 2020: Europe will reduce its $\mathrm{CO}_{2}$ emissions by $20 \%$, increase the share of RES (renewable energy sources) by $20 \%$ and increase the overall energy efficiency by $20 \%$ until 2020 compared to 1990 levels [1]. According to the latest reports, EU will achieve its goals related to the $\mathrm{CO}_{2}$ emission reduction and renewable energy sources share but additional efforts should be undertaken to achieve the planned increase in the energy efficiency [2]. This matter will have a crucial role in the upcoming strategy for the period 2020-2030, where additional increase of energy efficiency is planned, up to $27 \%$. The energy sector is a key component in achieving said goals since it is responsible for $79 \%$ of the EU's greenhouse gas emissions [3].

Combined heat and power (CHP) units in a combination with the district heating and cooling (DHC) systems can maximize the exploitation of the waste heat which is currently inefficiently released in the atmosphere $[4,5]$. Also, these systems have the ability of utilizing locally distributed renewable energy sources such as biomass, solar and geothermal energy which will additionally increase the $\mathrm{CO}_{2}$ reduction on a local level. District heating and cooling systems will have an important role in the future energy systems with a high share of an intermittent electricity production coming from renewable energy sources such as wind turbines and solar panels. In order to balance the grid, the excess of the electrical energy could be efficiently converted and stored as a thermal, by using storage and power-to-heat technologies, which include electrical heaters and heat pumps.

In the literature, the term "Fourth generation district heating" (4DH) is reserved for DHC systems which can tackle the problems of the future energy systems. Although 4DH implies increase of the overall thermal grid efficiency by implementing lower supply temperatures, they will also have to integrate power, thermal, gas and transport grids and at the same time utilize waste heat and renewable energy sources [5]. It was already shown that Denmark could integrate up to $50 \%$ of DH with the combination of large-scale heat pumps and heat storage thus achieving great impacts on the overall energy system [6]. The analysis in this work was mostly based around the cost of the system as a whole. Similar analyses have been conducted for other countries such as China [7], Sweden [8], UK [9], Italy [10] and France [11], among others. Project Heat Roadmap Europe proved that integration of heat savings, DH in a combination with heat pumps will result in the cheapest low-carbon heat sector in Europe [12]. Analysis of the DH and RES integration has also been carried out on a city level [13], including the comparative analysis of advanced and underdeveloped systems [14]. In addition to this, hourly optimization has been proved to

* Corresponding author: hrvoje.dorotic@,fsb.hr 
be an important approach in the development of $\mathrm{DH}$ systems [15]. Other research has also demonstrated the positive impact of energy efficiency measures related to DH such as the reduction of the supply temperature [16], utilization of smart grids [17], renewables [18] and hybrid systems [19] and socio-economic impact for final consumer [20] for example.

GIS (Geographical Information System) mapping has already been proven as a valuable tool for the analysis of energy systems. In the STRATEGO project, the heat demand mapping methodology has been developed [22]. Apart from the energy demand, GIS based methods have also been used for the mapping of potential energy sources [23].

This work will demonstrate heat demand mapping method and present the results of the analysis of the economic potential for the DH grid expansion. As the case study for this work, the city of Velika Gorica in Croatia has been selected.

\section{Method}

The work presented in this paper can be divided in the two main steps: heat demand mapping and expansion potential analysis.

\subsection{Heat demand mapping}

Heat demand consists only of the space heating demand. In order to carry out the head demand mapping process, publicly available data was used. In this way, the developed method could be used for mapping of the heat demand in other cities and regions. The mapping process is handled in 3 steps:

- mapping of the locations and surface areas of buildings,

- identification of the building heights,

- identification of the types of buildings.

Each step contains one layer of information. Combining building's surface area, height (number of floors) and type, its overall heating demand can be acquired. The obtained results can be further complimented with the addition of several layers of information for example population density, energy certificates and so on.

\subsection{DH expansion analysis}

The analysis of the potential for the expansion of the current DH system is based on an economic assessment to check if certain areas of a city can justify the installation of the new thermal grid. In order to make this assessment, five aspects are taken into the account:

- does a DH grid already exist in the area,

- the total heat demand in the area,

- levelized cost of heat ( $\mathrm{LCOH})$,

- potential revenue from the supply of heat,

- cost of a new grid in the area.
According to the available data, proposed analysis can be carried out on a building level or in a grid form, as shown below. In order to calculate levelized cost of heat, method described in [21] was used. Actual heat and capacity prices were used to estimate the potential revenue.

To calculate the total cost of the DH grid expansion, two sets of data are required: the length and discounted cost of pipes. This data can be obtained by calculating the average net surface area of the buildings relative to the ground surface areas as well as the distribution length relative to the net surface area of all connected users. The calculation is shown in Equation (1).

$$
L_{n g}=\left(L_{n u} / A_{c u}\right) /\left(A_{u} / A_{g}\right)
$$

Where $L_{n g}$ represents the necessary distribution length for a given surface, $L_{n u}$ represents the length of the existing distribution for the already connected users, $A_{c u}$ represents the net surface area of the connected users, $A_{u}$ represents the surface area of all potential users in the analysed area and $\mathrm{A}_{\mathrm{g}}$ represents the ground surface area. The grid expansion is considered economically feasible if the total income generated by new consumers is larger than the sum of the discounted investment in the new grid and the total cost of the thermal energy production. Also, it is important to notice that the investment cost of the substations hasn't been taken into the account.

\section{Case study}

Because of the general lack of data related to the building census in Croatia, part of the process has been carried out manually. Building's location and footprint have been acquired from OpenStreetMaps (OSM) database [24] as well as the online building census GEOPORTAL [25]. Total number of floors have been collected from the city itself by using energy audits and manual inspection. This approach was also used in defining building category. In total, 7 specific heat demand categories have been used, similarly to the Sustainable Energy Action Plan (SEAP) of the city of Velika Gorica [26]:

- Households - $193 \mathrm{kWh} / \mathrm{m}^{2}$ annually,

- Commercial buildings $-180 \mathrm{kWh} / \mathrm{m}^{2}$ annually,

- City companies - $275 \mathrm{kWh} / \mathrm{m}^{2}$ annually,

- Administrative buildings - $285 \mathrm{kWh} / \mathrm{m}^{2}$ annually,

- Child care and education - $232 \mathrm{kWh} / \mathrm{m}^{2}$ annually,

- Cultural buildings - $123 \mathrm{kWh} / \mathrm{m}^{2}$ annually,

- Other public buildings - $128 \mathrm{kWh} / \mathrm{m}^{2}$ annually.

Annual heat demand presented in SEAP was obtained by using the heat consumption data from the final users. Specific heat demands, shown above, don't include the the thermal energy needed for DHW preparation. The DH system Velika Gorica currently doesn't provide this service. 
All of the mentioned data has been added and processed in qGIS [27], a free to use and open access GIS tool.

\section{Results}

Fig. 1 shows the heat demand map of the city with a resolution of 100 by 100 meters to demonstrate heat demand densities. This resolution has been used in all subsequent studies.

Fig. 2 shows the existing natural gas and DH distribution (existing and officially planned) within the city. As it can be seen, the gas infrastructure is spread around most of the city while DH is concentrated generally in the city centre. Normally, areas already covered by natural gas would not present suitable locations for the expansion of DH due to the competition. In this case however, gas infrastructure has been ignored in order to demonstrate the method since no expansion would be plausible if it wasn't.

Fig. 3 shows the initial results of the analysis where all areas suitable for the exploitation of DH are shown. The analysis takes into the account the potential revenue, $\mathrm{LCOH}$ and cost of the DH grid expansion into consideration. In cases where DH grids already exist, the results were overridden and set as suitable regardless of the costs. Since some areas identified as suitable are dislocated from the identified centres, they were excluded. The final area deemed suitable is presented in Fig. 4.

The final results show that a total of $117,182 \mathrm{GWh}$ annually could be supplied by DH. This is a significant share of the total heating demand identified in the cities SEAP which equals 197,342 GWh. In the year 2008, district heating network delivered 56,242 GWh of thermal energy to the final customers, which was equal to $28 \%$ of the total heating demand [26]. This shows a great potential for a future district heating grid expansion. Thermal energy delivered by DH could be doubled, but besides a larger network, this will also require additional upgrades of the heat production facilities.

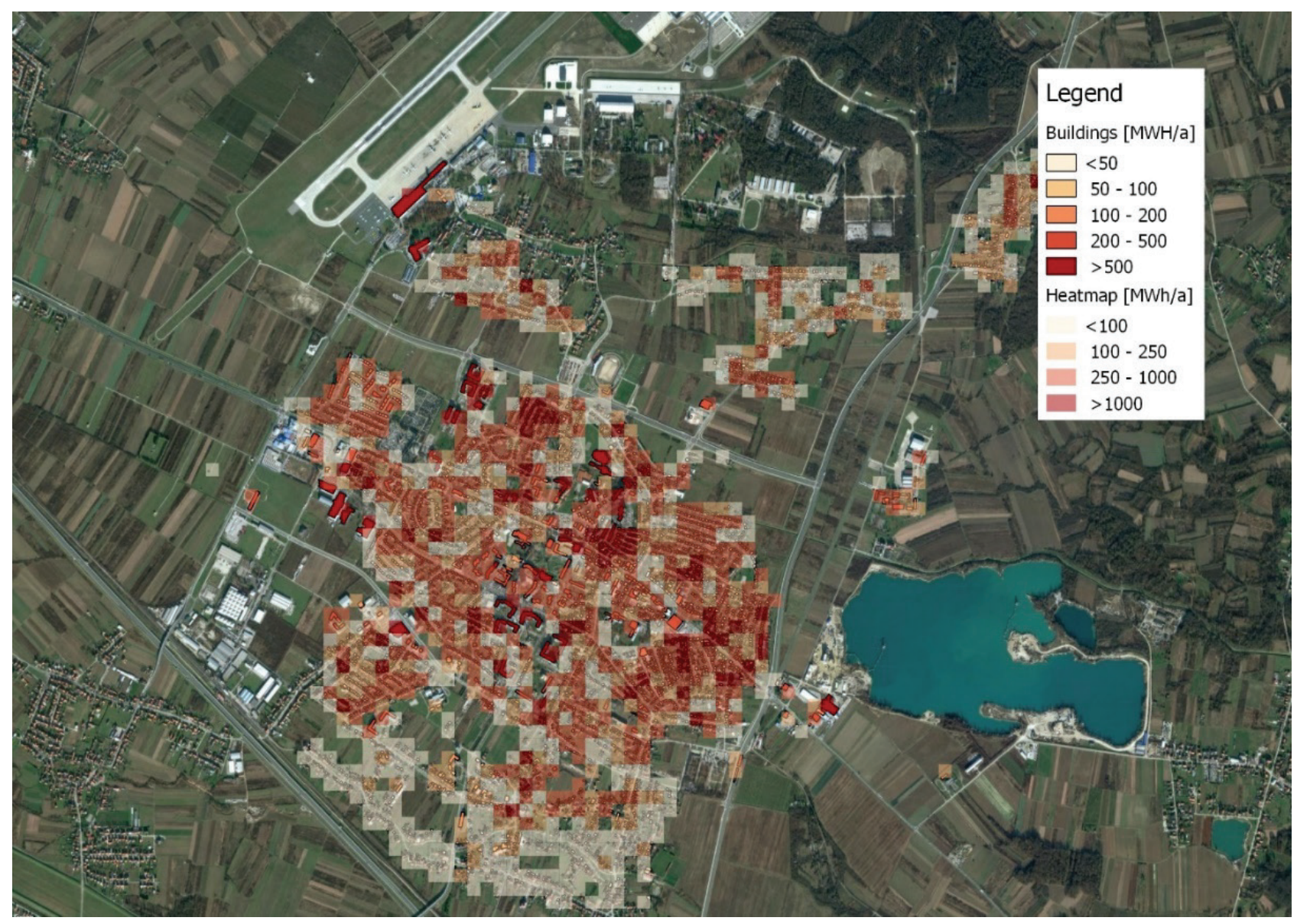

Fig. 1. Heat demand map of Velika Gorica. 


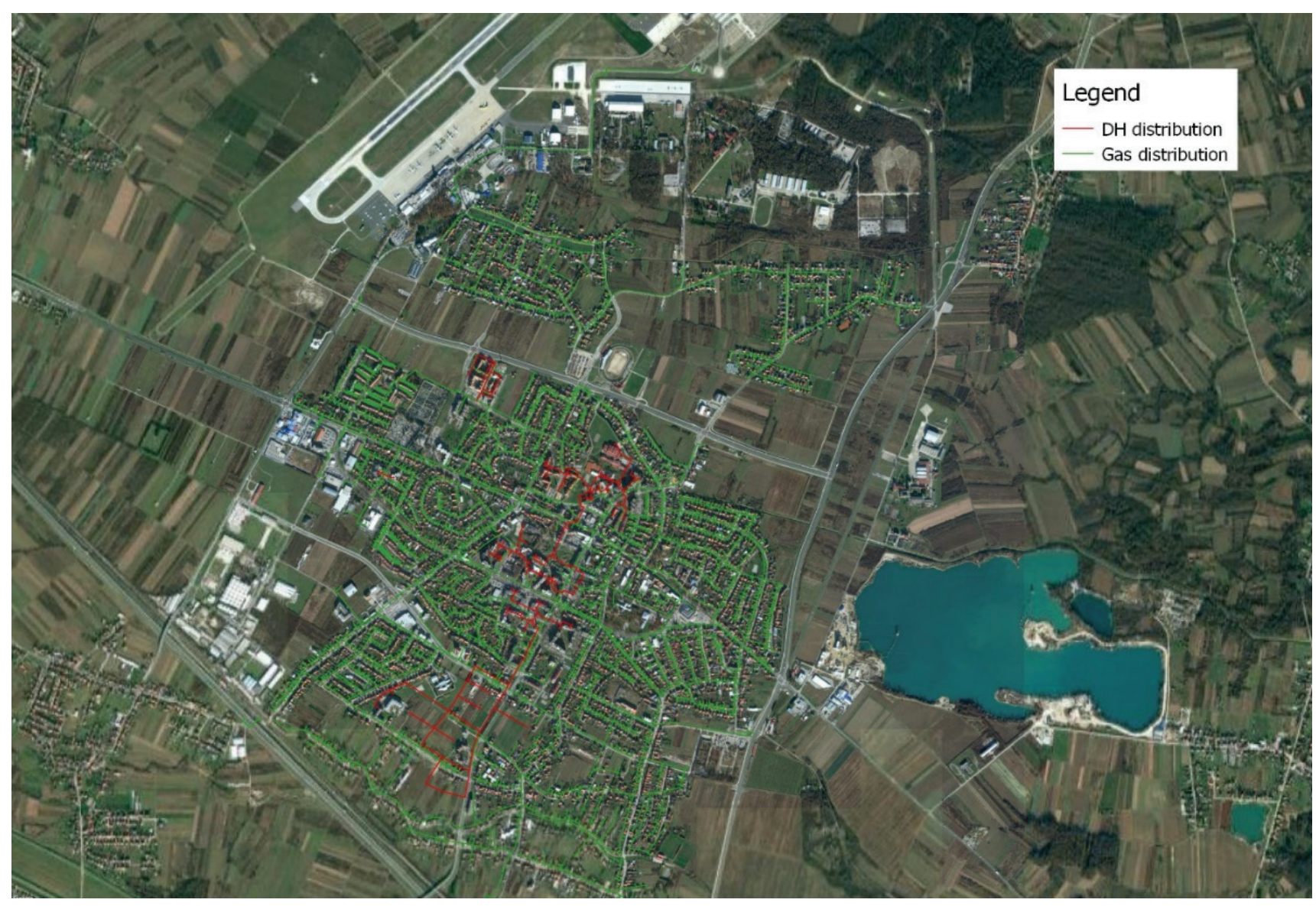

Fig. 2. Existing infrastructure in Velika Gorica.

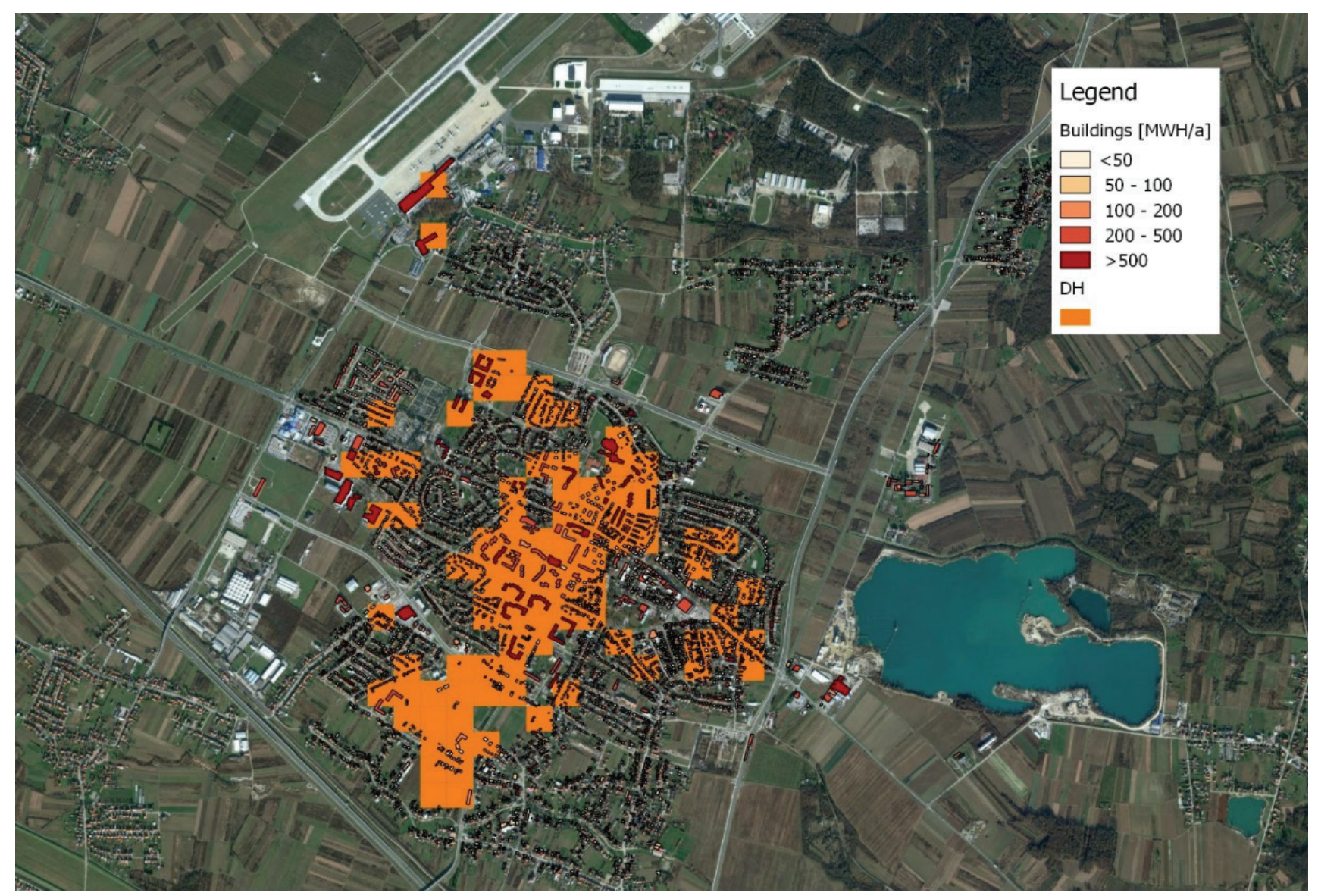

Fig. 3. Initial results. 


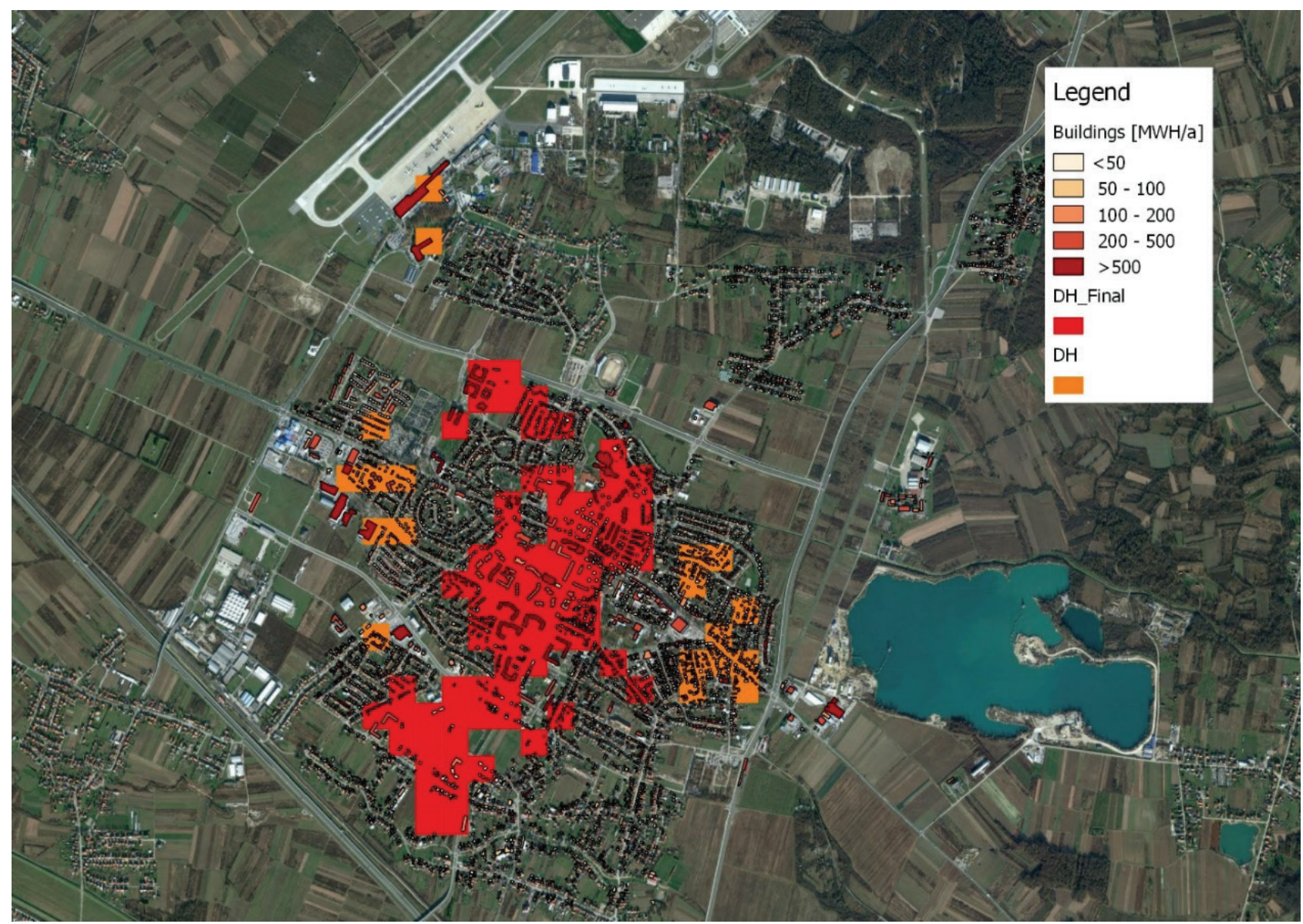

Fig. 4. Final results.

\section{Conclusion and future work}

GIS based methods have already been successfully used for energy demand and supply mapping. In this paper, mapped heat demand has been used for an analysis of the potential for the expansion of the district heating grid. As a case study, the city of Velika Gorica in Croatia has been chosen. To map the buildings and their heat demand, qGIS was used. The results have shown that a total of more than $117 \mathrm{GWh}$ could be supplied from the DH which is more than $59 \%$ of the total heating demand identified in the city's SEAP. Those results can't be applied to the real case since the natural gas grid already covers large share of that area.

The future work of this research will include refinement and validation of the input data and results, including the sensitivity analysis of the used data. This will be supplemented with a supply side analysis in order to more precisely analyse the potentials for the utilization of the DH and the resulting integration of the power and heat sectors.

\section{Acknowledgement}

Financial support from the European Union's Horizon2020 projects CoolHeating (grant agreement 691679) and PLANHEAT (grant agreement 723757), as well as the support from the RESFlex project funded by the Environmental Protection and Energy Efficiency Fund with the support of the Croatian Science Foundation are gratefully acknowledged.

\section{References}

1. European Commission, "20 20 by 2020 Europe's climate change opportunity," Brussels (2008)

2. European Commission, "A Roadmap for moving to a competitive low carbon economy in 2050," Brussels (2011)

3. European Environment Agency, “Annual European Union greenhouse gas inventory 1990-2012 and inventory report 2014," European Environment Agency (2014)

4. R. Lund, B. V. Mathiesen, App. Energy 142, 389-395 (2015)

5. H. Lund, S. Werner, R. Wiltshire, S. Svendsen, J. E. Thorsen, F. Hvelplund and B. V. Mathiesen, 4th Generation District Heating (4GDH): Integrating smart thermal grids into future sustainable energy systems, Energy 68, 1-11 (2014)

6. M. Münster, P. E. Morthorst, H. V. Larsen, L. Bregnbæk, J. Werling, H. H. Lindboe and H. Ravn, Energy 48, 47-55 (2012)

7. W. Xiong, Y. Wang, B. V. Mathiesen, H. Lund and X. Zhang, Energy 81, 274-285 (2015)

8. L. D. Lucia and K. Ericsson, Energy Res. Social Sci. 4, 10-20 (2014) 
9. S. J. G. Cooper, G. P. Hammond, J. B. Norman, Energy Inst. (2015)

10.N. Aste, M. Buzzetti, P. Caputo, Sustainable Cities and Society 14, 43-55 (2014)

11. P. Gabillet, Energy Policy 78, 189-197 (2015)

12. D. Connolly, H. Lund, B.V. Mathiesen, S. Werner, B. Moller, U. Persson, T. Boermans, D. Trier, P.A. Ostergard, S. Nielsen, Energy Policy 65, 475-489 (2014)

13. T. Novosel, T. Pukšec, G. Krajačić, N. Duić, Energy Procedia 95, 337-343 (2016)

14. D. Čulig-Tokić, G. Krajačić, B. Doračić, B. Vad Mathiesen, R. Krklec, J. Møller Larsen, Energy 93, 435-443 (2015)

15. M. Pavičević, T. Novosel, T. Pukšec, N. Duić, Energy, In press (2017)

16. Bolonina, G. Bolonins, D. Blumberga, Environ. Climate Technol. 14, 41-46 (2014)

17. M. A. Ancona, L. Branchini, A. De Pascale, F. Melino, Energy Procedia 75, 1208-1213 (2015)

18. M. Elci, A. Oliva, S. Herkel, K. Klein, A. Ripka, Energy Procedia 70, 560-567, (2015)

19. R. Mikulandrić, G. Krajačić, N. Duić, G. Khavin, H. Lund, B. V. Mathiesen, P. Østergaard, J. Sustain. Dev. Energy, Water and Environ. Syst. 3, 282-302 (2015)

20. L. Grundhahl, S. Nielsen, H. Lund, B. Moller, Energy 14, 1771-1778 (2016)

21. Levelized cost calculations, [Online]. Available: http://en.openei.org/apps/TCDB/levelized_cost_calcu lations.html [Accessed 05 May 2017]

22. Mapping the Heating and Cooling Demand in Europe, Work Package 2, Background report 5, STRATEGO project

23. R. Lund, U. Persson, Energy 14, 1-10 (2016)

24. OpenStreetMaps, [Online] Available: http://openstreetmap.org [Accessed 10 May 2016]

25. Geoportal, [Online] Available: http:/geoportal.dgu.hr/viewer/ [Accessed 10 May 2015]

26. City of Velika Gorica, "Sustainable Energy Action Plan of the City of Velika Gorica" (2011)

27. GIS, [Online] Available: https://qgis.org [Accessed 03 December 2016] 